\title{
Developing Children's Cultural Identities Through Play
}

\author{
Winnie Sin Wai PUI | ORCID : 0000-0002-2419-1759 \\ Undergraduate Supervisor, Faculty of Education, University of Cambridge, \\ Cambridge, United Kingdom \\ Visiting Academic, School of Education, University of Saint Joseph, \\ Macao, China \\ swwp2@cam.ac.uk;winniepui@knewstep.com
}

ZHANG Heyi | oRcID : 0000-0002-6625-6960

Institute (Department) of Early Childhood Education, Faculty of Education, Beijing Normal University, Beijing, PR China Corresponding author

heyizhang@bnu.edu.cn

\section{DING Ming}

Honorary Advisor, Zeng Cheng Qing Hua Kindergarten, PR China monicayin221@126.com

\author{
ZHONG Cai E \\ Principal, Zeng Cheng Qing Hua Kindergarten, PR China \\ 6o9466823@qq.com
}

\begin{abstract}
Play is an important vehicle for developing literacy, cognition, and social competence in early years settings. In this paper, a qualitative case study in a private kindergarten in China indicated how children could learn and appreciate their own culture in a thoughtfully designed play-based setting. Thirty kindergarten teachers from 15 classes consisting of 431 children in total participated in this study. Based on field notes, audio and video recordings, and teachers' self-reflective notes, the study explored the playbased setting within a curriculum framework, i.e. the Early-years Whole-person Global-mindset Curriculum Framework (EWGC). The results showed that the playbased setting supported young children to form their own cultural identities and enhanced children's development in general.
\end{abstract}




\section{Keywords}

play-based learning - early childhood education - cultural identities - Chinese kindergarten

\section{Introduction}

An increasing body of research evidence has linked play with young children's development and learning, which leads to significant growth in the recognition of the importance of high-quality provision amongst early years practitioners. Developmentally appropriate play-based settings allow for children's earliest discoveries through the interplay between the environment, objects, teachers, peers, and themselves. One may doubt how we can enable our children to feel connected with learning goals in early years settings. In fact, simply a piece of knowledge, a unique experience, an activity, a person or an object can make play-based learning meaningful. A powerful play-based setting includes materials that children are familiar with, so that children will have a clear idea of behaviour guidance and room arrangement (Reynolds, 1996). Within a powerful play-based environment, children can develop their interests and capabilities, to experience fun in the settings, and to discover and express their inner self. To improve the quality of play opportunities for children, a kindergarten in China initiated a play-based setting called 'Zeng Cheng Street'. This paper examined how 'Zeng Cheng Street' enhanced children's development and learning in a Chinese kindergarten, with a particular focus on the importance of play to the development of children's cultural identities.

\subsection{Culture and Identity in Early Childhood}

According to Cambridge Dictionary (2019), 'identity' refers to the qualities of a person or a group and how these make them different from others. The features might include ethnic background, tradition, occupation or other aspects of social identity (Siraj-Blatchford, 1996). In early years settings, Siraj-Blatchford (1996) defined child identity as the way that they feel about themselves and pointed out that children could achieve this in the learning process. Further, Lawrence (1988) and Gay (1985) emphasised the importance of supporting children in feeling positive about themselves, their ethnic identities, and cultural backgrounds. Positive self-concept and self-esteem contribute to children's social life and the development of key competences in early childhood.

Children develop their self-awareness from infancy to the preschool years and become curious about the differences between themselves and peers (Derman-Sparks, 2012). They also learn to understand the rules surrounding 
them and how to interact with others. For instance, children pay close attention to adults' feelings, verbal and non-verbal messages. Children might also feel uncomfortable with people with different cultural backgrounds. DermanSparks (2012) also indicated that children sometimes overgeneralise or misunderstand the true value of the differences among people. The reason is that young children have limited experience and strategies of processing information. For example, in some cultural contexts, children might learn and perceive that boys are stronger than girls. As a result, boys might be unfriendly to girls in kindergarten and try to ask their peers not to play with girls in a group (Skattebol, 2006). Moreover, it is argued that children begin to have a strong interest in fairness and start to develop their critical thinking from the age between three and four-year-old. Around this age, children easily make judgements about others that might sometimes lead to their peers' negative emotions, which is a proof of the beginnings of 'internalised superiority (IS)' and 'internalised oppression (IO)' (Derman-Sparks, 2012).

From the perspective of cultural psychology, it is important to investigate the link between person and culture, or in other words, self and cultural identities (Hviid \& Villadsen, 2014). One's understanding of culture shapes selfconcept and identity, and also impacts on one's learning (Nixon \& Comber, 2006). Children's recognition of the external environment, as their understanding of themselves, starts at very young ages. As young children are strongly interested and motivated to explore and make meaning of the world (Whitebread et al., 2017), it is worthwhile examining how to fulfill children's needs through educational practices. However, very limited research has conceptualised cultural identities. An empirical study examining children's cultural identities in educational contexts has pointed out that two key dimensions should be taken into account when defining and assessing cultural identities, i.e. 'what we are' and 'what interactions that we have with others' (Chen et al., 2010). In other words, cultural identities can be understood as 'my culture' and 'my culture vs. other cultures'. This conceptualisation has provided useful insights for research on children's cultural identities.

Supporting children to learn about self and cultural identities in early years settings is not merely an interactive process between teachers and children how a teacher guides children to develop self-perceptions, but also a learning process between children and others - how a child perceives and interact with others (Swann, 1985). Thyssen (2003) suggested that cultural and self-identity learning from a psychological perspective is not simply about understanding children's thoughts, feelings and motives, nor to simply find a way to 'teach' them all these concepts. Adults need to enable children to contribute to the common life and culture as active agents, i.e. supporting children in producing or reproducing ideas, meanings, and things in their social life after they 
become more aware of themselves and different cultural contexts. The ultimate goal of cultural and self-identity learning is to prepare children to acknowledge cultural differences and to look back in themselves and reflect on their own cultural identities and generate new thinking. In this article, we attempted to illustrate a case of a play setting supporting children in learning about themselves, their peers, and culture.

\subsection{Children Learn Culture through Play}

Many researchers (e.g. Reynolds, 1996; Skattebol, 2006; Baker, 2018) have highlighted that children can make meaning of cultural elements in a playful context. Reynolds (1996) showed a play-based curriculum that enabled children in Canada to retain traditional Inuit identity in daily life in terms of the provision of an authentic and meaningful environment.

"At play, both children and adults are challenged to invent new solutions to problems within flexible rules and rapidly changing scripts. Playing together, they practice negotiating their varied worldviews to create mutually satisfactory and increasingly complex understandings of their lives. In so doing, children are mastering skills and dispositions that they will need throughout their lives (Jones and Reynolds, 1995, p. 45).”

Baker (2018) showed the importance of learning through play to the enrichment of cultural heritage in a kindergarten setting in Abu Dhabi. This is a small-scale exploratory study relying on $5^{2}$ kindergarten teachers' interviews, indicating that children could learn through peer support instead of teacher guidance in a play-based setting. It also revealed that biased knowledge such as gender stereotypes could affect children's mindsets, which warned educators should enhance children's cultural competence through pedagogical practices in the early childhood classroom. A play-based setting is also a way for children to practise the social roles needed in adulthood. Dickson and Le Roux suggested similar findings, 'children are modelling substantial aspects of their play on adult activities and, in so doing, they are learning not only the social roles and cultural values typical in the culture but also the skills for community membership in which gender roles are distinct' (2012, p. 117). Besides, compared with the old days, Baker (2018) argued that children have a lack of opportunities to play, especially in outdoor settings. There were many chances for imaginative play for children in the past, especially during those days when children's life was not preoccupied with excessive ready-made toys.

Skattebol (2006) suggested that teachers should pay attention to the issue of hegemony in the world (e.g. hegemonic masculinity) when considering children's feelings in cultural learning or a context of cultural adaptation. One of 
the case studies described a teacher supporting a child with an Indian cultural background through his culture shock in a new country, Australia. In this case, the teacher tried to offer a comfortable play-based learning environment to minimise the little boy's negative emotions caused by the humongous difference among other cultures. Surprisingly, though the child appeared to be happy to assert a shared identification, he still preferred a social construct dominated by hegemonic masculinity. For example, he refused to play with girls even though they shared the same cultural and language backgrounds, perceived that a boy was more powerful than a girl, and tried to demonstrate his power over others. This unexpected outcome suggests the necessity of ensuring the development of cultural inclusion with a global mindset in a playful setting.

The above studies agree with Vygotsky's sociocultural theory (1978). The central idea emphasises children's construction of knowledge through interactions with others. Vygotsky also suggested that with support, children could advance from a level of performance in play to a level where they could have the potential of solving greater problems (Smidt, 2006). Vygotsky believed that children could have opportunities to stretch their creative minds and behaviours to reach a 'head taller than him/herself' through pretend play (Reynolds, 1996). Children acquire knowledge and learn how to make connections and make sense of the world around them (Cyrus, 2019). In line with Vygotsky's assertions, Thyssen (2003) has attempted to define two layers in cultural understanding in early childhood education. Level 1 concerns children's exploration and learning of new things practical life. Level 2 concerns children's abilities to expand the meanings relating to practical activities and objects. Research has consistently shown that through participation in a social setting, the individual becomes 'co-producer' and 'co-reproducer' of culture (Thyssen, 2003). Cultural learning is an active, innovative, and inventive process. At the same time, culture becomes more meaningful to children and supports their development of self-awareness.

\section{Background and Purpose of the Study}

According to the Early Learning and Development Guidelines for Children Aged 3 to 6 Years (Ministry of Education of the PRC, 2012), teachers should provide young children with rich opportunities for free play in the kindergarten. To improve the quality of children's play opportunities, a private kindergarten located in Guangzhou initiated a play-based setting named 'Zeng Cheng Street', which is one of the subprojects included in a curriculum reform project in the kindergarten. The kindergarten started to apply a 


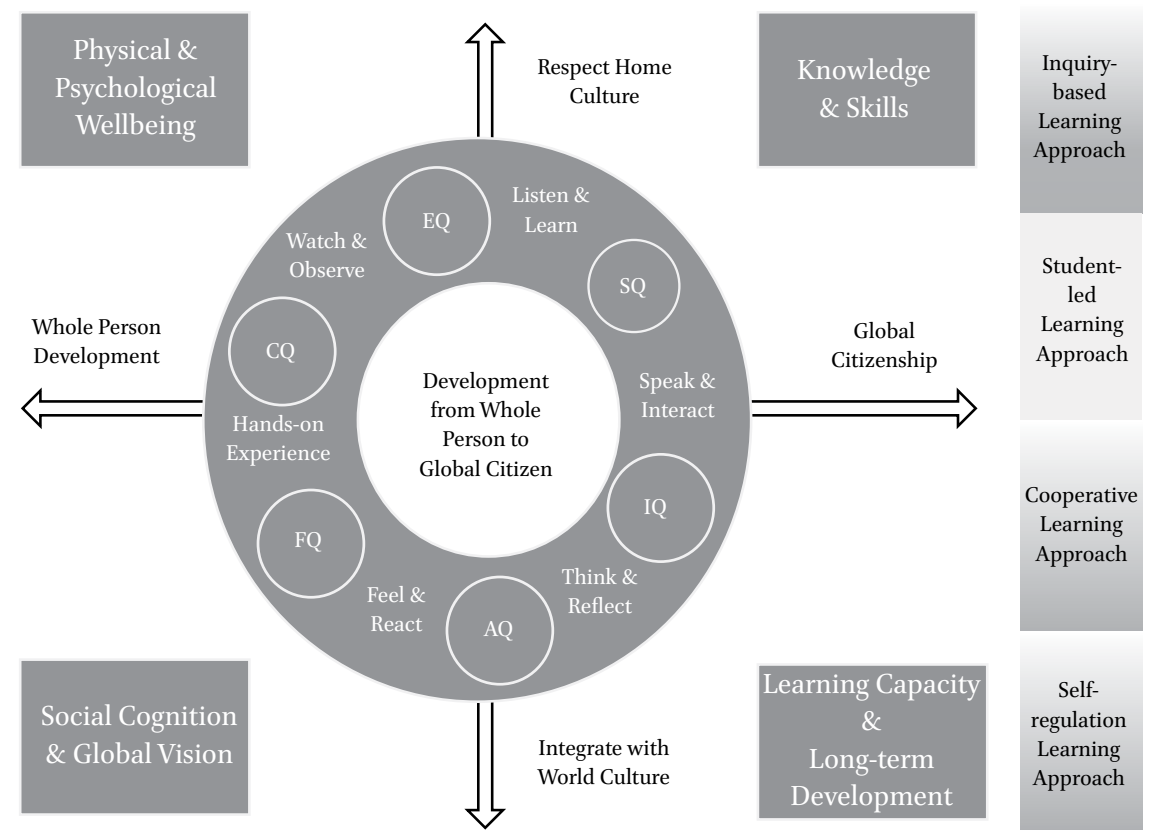

FIGURE 1 Early-Years Whole-Person Global-Mindset Curriculum Framework (EWGC) (Pui, Leung, \& Zhang, 2019)

kindergarten-based curriculum framework named the Early-Years WholePerson Global-Mindset Curriculum (hereafter referred to as EWGC, Pui, Leung, \& Zhang, 2019) at the beginning of 2019. The framework, as shown in Figure 1, is developed based on three principles: (1) retaining the advantages of kindergarten as well as the local culture; (2) enabling young children to become lifelong learners; and (3) broadening young children's horizons with globalmindset guidance. The present study aimed to explore how this play-based setting supported young children's development and learning, with a particular focus on children's cultural identities.

\section{3}

\section{Method}

\subsection{Participants}

This study is based on the aforementioned curriculum reform project conducted in the private kindergarten, which is graded as one of the 'first-class' kindergartens of Guangdong Province by the Department of Education in Guangdong. Thirty kindergarten teachers and 15 classes consisting of 431 children participated in this project. All the teachers hold an early years teaching qualification ranging from diploma level to undergraduate level. There are three age 
groups of children in the kindergarten, including 3-4 years old, 4-5 years old, and $5^{-6}$ years old.

\subsection{Data Analysis}

This study applied a case study approach to unfold a contemporary phenomenon in a real-life context (Yin, 2009). According to Meredith (1998), through case study research, two key outcomes can be achieved: gaining a holistic understanding of a phenomenon (i.e. the play-based setting in the study) and relevant theories through actual practice, and answering questions from different angles with the aid of the research tools (e.g. class observation, diary, etc.) applied in the case study. In short, case study research can enable researchers to gain a profound understanding of a complex and natural phenomenon.

As mentioned before, the case we discussed is extracted from an ongoing curriculum reform project. The data used in this study included field notes, audio and video recordings, and teachers' self-reflective notes. After everyday observation in the play-based setting, teachers conducted self-reflective notes twice every month to generate insights into how the phenomenon occurs in this play-based setting (Creswell, 2007).

Data analysis was conducted within the EwGC framework (Pui, Leung, \& Zhang, 2019), which illustrated the fulfilment of young children's learning and developmental needs in a cultural play-based setting. Table 1 presents the details of the competency indicators of the EWGC framework, including (1) Physical and Psychological Wellbeing; (2) Knowledge and Skills; (3) Social Cognition

TABLE 1 Four Competency Indicators of EWG C Framework

\begin{tabular}{|c|c|c|c|}
\hline $\begin{array}{l}\text { Physical \& } \\
\text { Psychological } \\
\text { Wellbeing }\end{array}$ & $\begin{array}{l}\text { Knowledge \& } \\
\text { Skills }\end{array}$ & $\begin{array}{l}\text { Social Cognition \& } \\
\text { Global Vision }\end{array}$ & $\begin{array}{l}\text { Learning Capacity \& } \\
\text { Long-term } \\
\text { Development }\end{array}$ \\
\hline $\begin{array}{l}\text { Physical } \\
\text { development }\end{array}$ & Literacy & $\begin{array}{l}\text { Understanding } \\
\text { oneself }\end{array}$ & Creative thinking \\
\hline Self-care & Mathematics & $\begin{array}{l}\text { Understanding } \\
\text { others }\end{array}$ & $\begin{array}{l}\text { Independent } \\
\text { thinking }\end{array}$ \\
\hline Communication & $\begin{array}{l}\text { Science and } \\
\text { technology }\end{array}$ & $\begin{array}{l}\text { Understanding } \\
\text { society }\end{array}$ & Problem solving \\
\hline $\begin{array}{l}\text { Emotional } \\
\text { competence }\end{array}$ & Arts & $\begin{array}{l}\text { Understanding } \\
\text { culture }\end{array}$ & $\begin{array}{l}\text { Self-reflective } \\
\text { thinking }\end{array}$ \\
\hline Social adaption & Sports & $\begin{array}{l}\text { Understanding } \\
\text { the world }\end{array}$ & Resilience \\
\hline
\end{tabular}




\begin{tabular}{|c|c|c|}
\hline & 1st Stage & 2nd Stage \\
\hline & $\begin{array}{l}\text { Example codes based on } \\
\text { learning objectives } \\
\text { within EWGC Framework }\end{array}$ & $\begin{array}{l}\text { Example discussion } \\
\text { regarding cultural } \\
\text { identities }\end{array}$ \\
\hline $\begin{array}{l}\text { Li Yun New Year's } \\
\text { Shopping Mall - (An } \\
\text { example from field } \\
\text { notes) }\end{array}$ & $\begin{array}{l}\text { Communication: The } \\
\text { children communicated } \\
\text { and collaborated with others } \\
\text { when pretended to sell food. } \\
\text { Emotional competence: The } \\
\text { children learned to express } \\
\text { and regulate their own } \\
\text { emotions as well as } \\
\text { understand others' } \\
\text { feelings through play. }\end{array}$ & $\begin{array}{l}\text { The play area provided } \\
\text { children with rich } \\
\text { opportunities to } \\
\text { communicate and } \\
\text { collaborate with peers. } \\
\text { During play, children } \\
\text { learned to consider others' } \\
\text { viewpoints, } \\
\text { which contributed to } \\
\text { the recognition of self } \\
\text { and others. }\end{array}$ \\
\hline
\end{tabular}

and Global Vision; and (4) Learning Capacity and Long-term Development. Under each competency indicator, there are different learning objectives, for instance, 'knowledge and skills' consisting of literacy, mathematics, and arts, etc. All these sub-indicators were used as a set of codes to arrange the collected data.

In this intra-case analysis, the EWGC framework was the key tool used for analysing the qualitative data. Table 2 shows an example of the data analysis process, which included two stages of data analysis. In the first stage, data were coded based on the learning objectives. In the second stage, we selected representative excerpts to discuss the effects of the play-based setting particularly on children's cultural identity and global citizenship.

The three-step process of Miles and Huberman (1994) was used to build up a valid set of results at the $1^{\text {st }}$ stage of data analysis. This first step is 'data reduction', referring to the processing of the mass of qualitative data we have collected such as field notes, audio and video recordings, and teachers' selfreflective notes. This is a process of reducing and organising data, for example, writing summaries, discarding irrelevant data, etc. The second step is 'data display', which means drawing conclusions from the large data set. Tables, charts, and diagrams could help to display the data effectively. This is a continual process in line with the philosophy of Creswell (2008)'s six-step 
qualitative data analysis model, which emphasised that data transcription and analysis was an interactive process. All transcribed notes should be sorted and sifted to find 'similar phrases', 'relationships between variables, patterns, and themes', 'distinct differences between subgroups', etc. (Miles \& Huberman, 1994). The last step is 'conclusion drawing/verification'. The initial conclusions need to be verified through different types of data references. All of these chunks of data allowed us to develop discussion at the 2nd stage of data analysis.

After the large data set was categorised into chunks, categorical coding was applied to make sense of the relevant data within the EWGC framework. In short, the direct interpretation was applied and extended our understanding through the EWGC framework. It helped to explore how a playful setting could support young learners' awareness of culture and self-identity and offer a learning environment for empowering their engagements with people in the world.

\section{4}

Findings

Our analysis starts with the overall characteristics of this play-based setting, i.e. Zeng Cheng Street. We then explored the role of different themed play areas in supporting children's development of cultural identities and other related skills through play.

Following the Early Learning and Development Guidelines for Children Aged 3 to 6 Years (Ministry of Education of the PRC, 2012) and the newly introduced EWGC framework, six learning areas were created, including performance area, art and design area, construction area, language and literacy area, cognitive area, and science and maths area. Various materials used in the areas were designed to stimulate children's learning motivation and imaginative thinking. Children could choose and use the materials following their own ideas. In all the themed play areas, handmade toys made from natural objects were provided. For instance, teachers and children used clay to make local products such as vegetables, fruits, and dim sum. These designs demonstrated the core ideas of Zeng Cheng street, i.e. using familiar materials to stimulate children's interests, motivation, and creativity. Instructions could be found in each themed area but without specific instructions, which allowed children to use their imagination to play with various combinations of materials.

In addition to high-quality materials designed to promote children's play and learning, the play-based setting greatly supported children's interpersonal communication and collaboration. Zeng Cheng Street was composed of 
TABLE 3 Themed Play Areas in Each Age Group

\begin{tabular}{|c|c|c|c|}
\hline & 5-6 Age Group & 4-5 Age Group & 3-4 Age Group \\
\hline 1 & $\begin{array}{l}\text { Meow Meow Sweet Soup } \\
\text { Store }\end{array}$ & $\begin{array}{l}\text { Zeng Cheng Specialty } \\
\text { Creative Park }\end{array}$ & 1978 Fishing Pond \\
\hline 2 & $\begin{array}{l}\text { Li Yun New Year's } \\
\text { Shopping Mall }\end{array}$ & $\begin{array}{l}\text { Zeng Cheng Specialty and } \\
\text { Souvenir Store }\end{array}$ & Li Yun Farm \\
\hline 3 & Li Yun Western Restaurant & $\begin{array}{l}\text { Zeng Cheng Li Xin Hair } \\
\text { Salon }\end{array}$ & $\begin{array}{l}\text { Zeng Cheng Grand } \\
\text { Stage }\end{array}$ \\
\hline 4 & $\begin{array}{l}\text { Lian Tang } \\
\text { Orchard }\end{array}$ & $\begin{array}{l}\text { My Style My Say My } \\
\text { Construction Workshop }\end{array}$ & $\begin{array}{l}\text { Li Village Creative } \\
\text { Cooking Workshop }\end{array}$ \\
\hline 5 & Pai Tan White Tea House & $\begin{array}{l}\text { Hand-made Jelly } \\
\text { Workshop }\end{array}$ & Building Joy \\
\hline 6 & $\begin{array}{l}\text { Take a Break in the } \\
\text { Hot Spring and Spa }\end{array}$ & My Impression of Li Village & $\begin{array}{l}\text { Lian Tang Barbecue } \\
\text { Shop }\end{array}$ \\
\hline 7 & $\begin{array}{l}\text { The Photography Studio } \\
\text { of Zeng Cheng District }\end{array}$ & $\begin{array}{l}\text { Zeng Cheng Grand } \\
\text { Stage }\end{array}$ & Leisure Bar \\
\hline 8 & Zeng Cheng Farmhouse & Village \& Farm Fun & Life Guru \\
\hline
\end{tabular}

themes areas respectively for three age groups. Each age group had eight developmentally appropriate themed play areas built on the traditional culture in Zeng Cheng (See Table 3). Although each age group consisted of five classes in the kindergarten, children were encouraged to play with peers from other classes in this setting. In the mixed-class setting, children had rich opportunities to interact with familiar and unfamiliar peers, which contributed to their social and emotional development.

Specifically, 'Li Yun New Year's Shopping Mall' was one of the most popular themed areas in the setting, aiming to improve children's understanding of the traditional food and culture related to the Chinese New Year. Through packing and pretending to sell sweets, snacks, dried goods, children had the opportunity to practise their fine motor skills by holding the kitchen tongs. They also learned to communicate with others, as shopkeepers and customers. Before beginning this one-hour play, these children needed to express what they wanted to be in this themed area. Some children wore the aprons to act as the shopkeepers. Miss Anna was the lead teacher in this group. She found that during the playtime, children had opportunities to learn to regulate their emotions and to respect others' feelings. 
"... the game has begun for 10 mins... Jason saw that one of the customers doesn't queue up to check out, as a result, he was impatient and shouted, "Please queue up first!". At the same time, Jack expresses that he wanted to be a cashier rather than a customer. Erica told me that she was not willing to exchange the role with Jack. I suggested that we could add a cashier assistant role in this game. After a discussion with Erica, Jack was happy to be Erica's little assistant."

Miss Anna found ways to support children in expressing their ideas (e.g. choosing the roles they wanted to act, both in Erica and Jack's cases). She seized the chance to teach the children to respect their peers' ideas and make a compromise in unexpected situations. She emphasised that it is important to listen to children's voices and support them based on their needs rather than overcontrol children from an adult's perspective. The inevitable conflicts during play allowed for children's learning of interpersonal communication. In this context, the young learners not only express their thoughts but also experienced how to interact with others and resolve conflict. Furthermore, in Miss Anna's reflective notes, she suggested that it would be great if the teachers could support the children to learn the traditional food items in the store and offer basic guidance for the different roles in the social setting. This might help increase the complexity and the quality in this play-based setting, where higher-order cognitive skills could be promoted.

Similar situations occurred in another context within the themed play area 'Village \& Farm Fun'. In 'Village \& Farm Fun', most of the children chose to be a chef rather than the customers. They used toy vegetables, meat, and fruits to prepare, cook, and serve a proper local dish in Zeng Cheng. As the little customers could walk around these themed play areas, there was no guaranteed number of customers in each themed play area. Facing the situation of no customers to be served, Miss Abbey suggested the children offering a takeaway service. In this playful context, children could acquire cultural knowledge such as the traditional Zeng Cheng farm food, while practicing their problemsolving skills when facing challenges. This is consistent with the overall goal of the curriculum reform project, which attempted to not only promote children's knowledge and skills but also contribute to children's development of cultural identities and a global mindset.

Also, the excerpt from 'The Photography Studio of Zeng Cheng District' further illustrated children's cultural learning in the play-based setting. Miss Bella found that "although children can only use the ready-made photos during play as it is impossible for teachers to print out the photo immediately, children still enjoy getting the ready-made photo after they pretend to take a photo of the sightseeing spots. I am surprised by this." By pretending to take pictures of the 
historical and cultural sites, children's understanding of the connections between themselves and the local culture could be improved in this play area. From the perspective of cultural psychology, individuals' development is cultural in nature (Haviid \& Villadsen, 2014). Based on this premise, it is crucial to enhance children's awareness of themselves and cultural practices in the early years.

'Building Joy' is a themed play area for the youngest group. Apart from the common construction materials such as giant Lego bricks, teachers provided natural materials such as tree branches, shells, and pinecones for children. Besides, following the EWGC framework which attempted to enhance the children's awareness of global issues such as environmental protection, teachers also prepared some recycled materials such as cans and cardboard boxes. The wide range of objects offered in this area supported different aspects of children's development and learning. As for knowledge and skills, the amount of playful exploration, construction, and tool use was beneficial to children's development in mathematical and special abilities, language skills, problem solving, etc. (Whitebread et al., 2017). Concerning children's development of cultural identities, the playful experiences in this area encouraged children to interact with others and the environment. For example, before a child went away to move some objects to her own building area, she asked other children to safeguard what she already built. In the meantime, she showed her willingness to help others. This example showed that children began to understand how to achieve certain goals through communication and collaboration in a social setting. Chen et al. (2010) claimed that cultural identities could be understood as a matter of perspective taking, which concerns interpersonal relations, moral reasoning and social problem solving. As demonstrated by children's joyful experiences in the play-based setting, the development of cultural identities and other abilities does not occur in isolation, but through interactions with other people.

\section{5}

\section{Conclusions}

The present study offered a novel perspective for researchers and educational practitioners to reflect the role of play in children's cultural identities in the context of early childhood education. In addition to cultural identities, the play-based setting provided opportunities for children to develop other skills highlighted in the curriculum framework. Such a 'real-life' playful setting encourages children to actively make sense of what they observe and learn, and more importantly, meets children's developmental needs to play freely at the early stage of life. 
Using a case study approach, the present study was unable to determine the influence of a play-based setting on children's cultural identities and other developmental outcomes. Empirical research with larger sample size is therefore needed to examine the predictive power of play. Furthermore, the play-based setting in the study only represented the local culture. It would be worthwhile examining how practitioners could guide children to learn and respect other cultures in play-based settings. The development of cultural identities is an ongoing process. Through continuously interacting with the social and cultural environment, children can form a global mindset of cherishing their own cultural heritage, and meanwhile, embrace other cultures and values.

\section{References}

Baker S.F. (2018). Shaping Pedagogical Approaches to Learning through Play: A pathway to enriching culture and heritage in Abu Dhabi kindergartens. Early Child Development and Care, 188(2), 109-125.

Biddle, G., K.A., Garcia-Nevarez, A., Roundtree Henderson, W.J., \& Valero-kerrick, A. (2013). Early childhood education: Becoming a professional. sAGE Publications.

Cambridge Dictionary (2019). Meaning of 'identity'. https://dictionary.cambridge.org/ dictionary/english/identity.

Chen, H.P., Lien, C.J., Annetta, L., \& Lu, Y.L. (2010). The Influence of an Educational Computer Game on Children's Cultural Identities. Educational Technology \& Society, 13(1), 94-105.

Creswell, J.W. (2007). Qualitative Enquiry and Research Design: Choosing among Five Approaches. Sage Publications.

Creswell. J.W. (2008). Educational Research: Planning, Conducting, and Evaluating Quantitative and Qualitative Research ( $3^{\text {rd }}$ ed.). Merrill.

Cyrus (2019). Learning through Play. https://www.cyrus.net.nz/musings/23-learningthrough-play.html.

Swann, B.M.S. (1985). Education for All: the report of the committee of inquiry into the education of children from ethnic minority groups. HMsO. http://www.education england.org.uk/documents/swann/swannig85.html.

Derman-Sparks, L. (2012). Stages in Children's Development of Racial/Cultural Identity and Attitudes. UUA General Assembly 2012. https://www.uua.org/sites/live-new.uua .org/files/documents/derman-sparkslouise/1206_233_identity_stages.pdf.

Dickson, M., \& Le Roux, J. (2012). Dickson, M., \& Le Roux, J. (2012). Why do Emirati Males become Teachers and how do Cultural Factors Influence this Decision? Learning and Teaching in Higher Education: Gulf Perspectives, 9(2). http://lthe.zu.ac .ae/index.php/lthehome/article/viewDownloadInterstitial/111/35. 
Gay, G. (1985). Implications of Selected Models of Ethnic Identity Development for Educators. Journal of Negro Education, 54(1), 43-55.

Hviid, P., \& Villadsen, J.W. (2014). Cultural Identities and Their Relevance to School Practice. Culture \& Psychology, 20(1), 59-69.

Lawrence, D. (1988). Enhancing self-esteem in the classroom. Paul Chapman.

Meredith, J. (1998). Building Operations Management Theory through Case and Field Research.Journal of Operations Management, 11(3), 239-256.

Miles, M.B., \& Huberman, A.M. (1994). An Expanded Sourcebook: Qualitative data analysis (2nd). Sage Publication.

Ministry of Education of the People's Republic of China. (2012). Early Learning and Development Guidelines for Children Aged 3 to 6 Years. https://www.unicef.cn/sites/ unicef.org.china/files/2018-10/2012-national-early-learning-developmentguidelines.pdf.

Nixon, H., \& Comber, B. (2006). Differential Recognition of Children's Cultural Practices in Middle Primary Literacy Classrooms. Literacy, 4o(3), 127-136.

Pui, W.S.W., Leung, S.K., \& Zhang, H. (2018). Early-Years Whole-Person Global-mindset Curriculum framework. Exploring the Most Suitable Plan for Zeng Cheng Qinghua Kindergarten from all Major International Frameworks. Unpublished. Knew STEP Education Group.

Reynolds, G. (1996). Understanding culture through Play. Child Care Information Exchange, https://www.chezmadamehelene.com/uploads/1/1/3/o/11301496/play _and_culture.pdf.

Siraj-Blatchford L.I. (1996). Values, Cultures and Identity in Early Childhood Education. International Journal of Early Years Education, 4(2), 63-69.

Skattebol, J. (2006). Playing Boys: The body, identity and belonging in the early years. Gender and Education, 18(5), 507-522.

Smidt, S. (2006). The Developing Child in the $27^{\text {st }}$ Century. A Global Perspective on Child Development. Oxon.

Thyssen, S. (2003). Child Culture, Play and Child Development. Early Child Development and Care, $176(3), 589-612$.

Vygotsky, L.S. (1978). Mind in Society. Harvard University Press.

Whitebread, D., Neale, D., Jensen, H., Liu, C., Solis, S.L., Hopkins, E., Hirsh-Pasek, K. \& Zosh, J. (2017). The Role of Play in Children's Development: a review of the evidence. https://www.researchgate.net/profile/Hanne_Jensen8/publication/325171537_The _role_of_play_in_children's_development_a_review_of_the_evidence/ links/5afcra4ba6fdccacabig99eb/The-role-of-play-in-childrens-development-areview-of-the-evidence.pdf.

Yin, R. (2009) Case Study Research:Design and methods (4 ${ }^{\text {th }}$ ed.). Sage Publications. 